\title{
CORPORATE ROLES AND RESPONSIBILITIES IN SOCIETY AND RESPECTIVE ETHICAL RULES
}

\author{
Prof. Dr ALBA DUMI ${ }^{1}$ \\ Dr GERTI DAJÇI ${ }^{2}$ \\ ${ }^{I}$ Vice Dean TBU University Tirana, Albania \\ ${ }^{1 / 2}$ Tirana Business University College Head of Management Department
}

\begin{abstract}
The purpose of CSR is to make managers, consultants, academics and many non-profit governmental organizations aware and focusing on the social, environmental and ethical responsibilities of business. It is important to understand that corporations are in business for profits, but in accordance with the environment and other respective ethical rules. Milton Friedman once stated that profits are the chief purpose of business. Profits do matter, but today we know more about how business contributes to society. Good firms bring innovation to the marketplace, which facilitates their growth. Innovative, growing firms generate economic growth and employment, which, in turn, greatly improves people's lives (Ahlstrom, 2010) $)^{1}$. The concept of CSR is a relatively new phenomenon started in the early 1970 's. As companies have grown to understand the importance of CSR to them as an entity and to our society in general, the relationship between the company's and its stakeholders has evolved into an understanding of the importance of a comprehensive and meaningful CSR policy. The content of this paper will explore this relationship and the benefits that will accrue to all the parties involved in this partnership. The impact and benefits that CSR policies have on society; the environment; employees, the government regulation, and others related parties will be examined.
\end{abstract}

\section{Introduction}

In the early 1970s, the concept of corporate social responsibility (CSR) was introduced. Around 1989, the use of "stakeholder," those impacted by an organization's activities, was considered a more valid term to describe corporate owners beyond shareholders.

The purpose of this reflection paper is to describe some of the roles and responsibilities of the organizations in society. The purpose of CSR is to make managers, consultants, academics and many non-profit governmental organizations aware and focusing on the social, environmental and ethical responsibilities of business. It is important to understand that corporations are in business for profits, but in accordance with the environment and other respective ethical rules. Milton Friedman once stated that profits are the chief purpose of business. Profits do matter, but today we know more about how business contributes to society. Good firms bring innovation to the marketplace, which facilitates their growth. Innovative, growing firms generate economic growth and employment, which, in turn, greatly improves people's lives (Ahlstrom, 2010). As corporations pursue growth through globalization, they have encountered new challenges that impose limits to their growth, potential profits, and social responsibility. According to Dr. Younkins $(2000)^{2}$, the author of "Capitalism and Commerce", the concept of corporate social responsibility can be traced to actions taken and pronouncements made by American business leaders as strategic responses to antibusiness sentiments that developed during the late 1800s and early 1900s. The goal of these business leaders was to promote corporations as forces for the social good and thereby lessen the threat of government intervention and regulation. The environment has become a big issue for many companies because of the recent Copenhagen conference and the Stern report $(\mathrm{Katz}, 2010)^{3}$. Stakeholders are an important ingredient in the development of a corporation's CSR policies. Typically, the largest numbers of stakeholders are the employees. Companies have recognized over the

\footnotetext{
${ }^{1}$ Ahlstrom, D. (2010). Innovation and Growth: How Business Contributes to Society

${ }^{2}$ Younkins, E. (2000). The Free Radical. Individual Rights, Social Responsibilities, and Corporations

${ }^{3}$ Katz, M. (2010). CSR Strategy in Developing Countries. CSR: Strategizing for the Future
} 
years that employees are a valuable asset and can bring a lot of experience, knowledge and innovation for the benefit of the company. Kantor and Wells (2004) $)^{4}$, in their book "Innovation" stated the following:

"I'm often asked what the first step is toward creating a challenging, innovative environment. Don't try to mastermind it from the top. Put together a team of your most talented people. Give them a mission: to make the company a more exciting place to work. Unleash their creativity. They'll come back to you with dozens of ideas, and some of them will be brilliant. Ask for company-wide input on these ideas. You're liberating people's imaginations. That in itself creates a more challenging environment - and a momentum is started."

\section{GENERAL INFORMATION AND PURPOSE OF THIS PAPER RESEARCH:}

The company's shareholders are also the owners of the company and therefore they have an interest in making sure the company does well, financially and also deals appropriate with environmental and social issues that involve the corporation. Customers and vendors also have a vested interest in the success of the company and it is important that all of these constituents communicate with the other stakeholders and the company to address any issues or concerns that they may have regarding CSRs.

CSR is the integration of business operations and values, where the interests of all stakeholders including investors, customers, employees, the community and the environment are reflected in the company's policies and actions (Weltzer, 1994) 5

Stakeholders include a corporation's employees, shareholders, suppliers, customers and their families in addition to people in communities where the corporation or its plants are located. Corporations provide jobs, which contribute to the health of local economies. Environmental issues, including pollution prevention and energy conservation, affect the health and wellbeing in communities in which an enterprise is located. Stakeholders also include those being educated in local school systems, sometimes for employment at the corporation. Additional stakeholders include local government \& community leaders.

Over the years, the practice of corporate social responsibility has been debated and criticized. Some feel there is a strong business argument in favor of CSR because corporations' benefit by moving from short-term profit sensitivity to a longer-term outlook that incorporates other viewpoints and potential innovations that can contribute to desirable outcomes. These outcomes include innovation that leads to additional profitability, and successful recruitment and retention of talented employees.

Those who disagree feel that CSR distracts from the basic economic role of businesses. Some say it is superficial and can obscure unpalatable or underhanded corporation activity. Like anything, CSR programs can be beneficial if genuinely implemented with objectives that don't weaken the corporation. Or misuse can pervert the goals this concept was intended to achieve. Corporate social responsibility was intended to encourage fair practices with all of a corporation's stakeholders.

\section{HYPOTHESES AND THE AIM OF THIS PAPER RESEARCH}

There have been cases when companies like Wal-Mart have been criticized for underpaying its employees and not providing adequate health benefits, but Costco, in a similar business, has also received criticism for the opposite reason - for paying its employees a living wage and benefits. Critics say this practice is shortchanging shareholders.

Costco's founder Jim Senegal defended his company's wage and benefits practice, "We have a very low turnover in our company...we take great pride in the fact that people join us and they stay with us. Our attitude has always been that if you hire good people and provide good wages and good jobs and more than that - if you provide careers - that good things will happen to your company. I think we can say that that has been proved by the quality of

4 Kantor, R., \& Wells, R. (2004). Book: "Innovation: Breakthrough thinking at 3M (etc.)."

${ }^{5}$ Wetzler, P. (1994). History of Post-It notes - please read this, he's not only an inventor, he's a sales guy, too! 
people that we have and how they have built our organization." (Mcgreson, 2006) ${ }^{6}$. He also addresses the shareholder in a straightforward fashion, "In the final analysis the shareholders own the company and they are the boss...we have done a pretty good job of rewarding our shareholders. We sell for a very healthy price relative to the multiple on our stock. I think that criticism from the marketplace is not inappropriate. I think that is what keeps us all on our toes. We are not fighting the system. The system works pretty well for us and we think it has worked pretty well for our company and our shareholders." (Mcgreson, 2006).

\section{Implementation of CRS}

Community-based development projects are one way CSR can be implemented, leading to sustainable development both here and abroad. Instead of making a contribution to an existing organization, supporting community-based development programs in underprivileged areas with a focus on education and skill development provides both children and adults with the tools to become self-sufficient and good citizens (Maden, 2008). ${ }^{7}$

Encouraging a company culture of innovation gives employees the opportunity to be creative in the development of new services or products. Programs can provide financial incentives to employees for contributions that contribute to the company's profitability. In this way, shareholders are happy with a greater return on their investment. Employees are happy working in an innovative environment, and recruiting and keeping the best employees is easier.

\section{LITERATURE AND REVIEW}

In television commercials, the head of S.C. Johnson talks about using trash from a nearby landfill to power its manufacturing plant, an obviously powerful statement about sensitivity to the environment. This very possibly started with a speech made by H.F. Johnson, Sr. in 1927, where he stated, "The goodwill of the people is the only enduring thing in any business. It is the sole substance...the rest is shadow." (Johnson, 2007) ${ }^{8}$.In 1976, the company stated its guiding philosophy, a statement of expectations for operations around the world, in "This we believe," a CSR statement from a company that consistently ranks in the best companies to work for. From their website today: "In this we believe: we express our beliefs in relation to five groups of people to whom we are responsible and whose trust we must continue to earn:

- Employees: We believe our fundamental strength lies in our people.

- Consumers: We believe in earning the enduring goodwill of the people who use and sell our products and services.

- General Public: We believe in being a responsible leader in the free market economy.

- Neighbors \& Hosts: We believe in contributing to the well-being of the countries and communities where we conduct business.

- World Community: We believe in improving international understanding." http://www.scjohnson.com/family/fam_com_phi.asp(2)9

\section{Auditing and reporting}

Some countries around the world require CSR reporting, but determination of social and environmental performance is difficult. Many companies now produce outside audited annual reports that cover CSR issues but the reports vary widely in evaluation methodology. Some critics dismiss these reports, remembering the CSR reports of Enron and tobacco corporations.

As corporations pursue growth through globalization, they have encountered new challenges that impose limits to their growth and potential profits. There are many Governments regulations that assist the consumers and organizations. Governmental policy that assists consumers and the organization is the Public Company Accounting Reform and Investor Protection Act of 2002 also known as the Sarbanes-Oxley Act of 2002. This Act was enacted in

\footnotetext{
6 Mcgreson, P. (2006). Costco story

7 Maden, J. (2008). Wikipedia definition of CSR

8 Johnson, S. C. (2007, April 11). (IV). Retrieved from <http://www.scjohnson.com/community/default.asp >

9 Johnson, S. C. (2007, April 11). (IV). Retrieved from <http://www.scjohnson.com/community/default.asp>
} 
response to corporate accounting scandals that has caused millions of investors, consumers, and most organizations to lose their life savings and investment portfolio. This Act was also enacted to "protect investors by improving the accuracy and reliability of corporate disclosures made pursuant to the securities laws, and for other purposes." (Sarbanes-Oxley Act of 2002) ${ }^{10}$. Government should set the agenda for social responsibility by the way of laws and regulation that will allow a business to conduct them responsibly.

In 2002, the Sarbanes-Oxley Act was enacted in the United States in response to corporate and accounting scandals at Enron, Tyco and WorldCom, among others. Because of these scandals, stakeholders lost billions of dollars and the public's confidence in the capital markets took a beating. (Atkins, 2006) ${ }^{11}$.

\section{Business benefits}

The benefits of CSR for corporation vary from company to company. There are reports that find correlation between social/environmental performance and financial performance. But evaluation strategy and timeline differ widely, with some companies unable to get beyond a short-term outlook while others see clearly that addressing longterm issues can long-term benefits, too.

Many businesses encourage charitable efforts and community volunteering among their employees, and are able to take advantage of the improved public image without allocating company resources. Other companies set the example with established programs that benefit the community, and where on occasion, employees join the effort. A Midwest company, Barr Engineering, covers the wages of employees who help build Habitat for Humanity homes. Both the company and the employee contribute something for the mutual benefit of giving back to the community. Quite a difference from watching a company build its good will on the shoulders of employees pressured to volunteer on their own time (Michels, 2008) ${ }^{12}$. It is companies where a CSR program is carefully thought out and supported at the highest levels that achieve the best results in these areas.

\section{Human Resources}

A strongly supported CSR program can aid recruitment of the best employees, especially in competitive job sectors. Potential recruits frequently want to know about a company's social responsibility practices, and having a good program in place can provide a distinct advantage. (Hetzog, 2004) $)^{13}$

\section{Risk Management}

Managing risk is an important part of any company's long-term viability. A company's reputation and good will, built up over many years, can be ruined in a flash through environmental accidents, corruption and sabotage (Hetzog, 2004).

Often it takes a crisis to precipitate attention to CSR, like the Exxon Valdez incident in Alaska in 1989. Lead poisoning in paint used by Mattel required a global recall of toys and forced the company to develop new risk management and quality control processes. (Atkins, 2006). ${ }^{14}$

A proactive example would be Tylenol. In 1982, Truetv reported that Tylenol products were randomly poisoned with cyanide by an individual who tried to extort $\$ 1$ million from the company (truetv, 1982) ${ }^{15}$. Several people died. In response to the deaths, Johnson and Johnson immediately issued a nationwide alert to the public, doctors and distributors of the drug. They also issued a recall of 31 million Tylenol bottles, costing about $\$ 125$ million. They established a crisis hotline, so consumers could obtain the latest information about the poisonings, safety measures and any other information concerning the drug. Around the same time, the company inspected the factories where the tainted bottles were produced to see if the cyanide was somehow put into the capsules during production. They ultimately instituted safety packaging for new products. Their quick and ethical reaction to the crisis allowed them to regain $98 \%$ of the market they had before the crisis (Atkins, 2006). Building a genuine culture of 'doing the

10 Sarbanes-Oxley Act of 2002, Public Law 107-204

11 Atkins, B. (2006, November 16). Forbes: "Is Corporate Social Responsibility Responsible?"

12 Michels, D. (2008). From genetic engineering \& biotechnology news (a shot at the idea):

13 Hetzog, W. (2004, March 16). 3M. Retrieved from http://solutions.3m.com/wps/portal/3M/en_US/businessconduct/bcmain/ceo/ceochairma n/

14 Atkins, B. (2006). Forbes: "Is Corporate Social Responsibility Responsible?"

15 Truetv (1982). Tylenol Case 
right thing' within a corporation can offset risks and deflect unwanted attention from regulators, courts, governments and media.

\section{Brand Differentiation}

Companies look for a unique selling proposition which makes them memorable in the eyes of those who use their products or services. CSR can help build customer loyalty by promoting ethical values system-wide and earning a reputation for best practices in all areas of their business. (Kantor \& Wells, 2004).

\section{Ethical Consumerism}

As global population increases, so does pressure on limited natural resources required to meet rising consumer demand. Consumers are becoming more aware of the environmental and social implications of their dayto-day consumer decisions and are beginning to make purchasing decisions related to their environmental and ethical concerns. While this practice is far from consistent or universal, it does tend to favor companies with an active CSR program.

\section{Socially Responsible Investing}

The role among corporate stakeholders to work collectively to pressure corporations is changing as shareholders and investors themselves exert pressure on corporations through socially responsible investing. (Wetzler, 1994). Others leverage the power of the media and the Internet to impact corporate behavior. Through education and dialogue, the movement to hold businesses responsible for their actions is growing. Companies could bring business and society back together if they redefined their purpose as creating "shared value"--generating economic value in a way that also produces value for society by addressing its challenges. A shared value approach reconnects company success with social progress (Porter \& Kramer, 2011). ${ }^{16}$ It is certainly within the responsibility of an organization's leaders to develop socially responsible practices, but the nature of industry and the institutional environments in which organizations exist jeopardize the competitiveness of organizations that implement such practices (Delios, 2010). ${ }^{17}$

\section{The Global Market}

Corporations encounter new challenges when pursuing growth in the global market, which sometimes limit growth and potential profits. From a CSR perspective, international competition forces an examination of their own company's labor practices in addition to the entire supply chain. In such an environment global politics, geo-politics, does tend to intrude as we make our arrangements to take our businesses to new national audiences, to work in different countries, to invest in different parts of the world, to dispatch our staff around the world, or care for overseas staff in our own domestic firmament. The child labor, speech and press restrictions, executions and imprisonment without trial, beatings, government expropriation of property and countless other rights violations, which are part of daily life in non-Western culture, will not go away - not until reason, individualism and worldly happiness are admired and pursued, at least implicitly (Peikoff, 2010).$^{18}$ Government regulations, taxes, environmental restrictions and differing labor standards are problems that can come with price tags in the millions of dollars. While some view ethical issues as a costly barrier, others use CSR methodologies as a way to gain public support for their presence and a competitive advantage by using their social contributions to provide a subconscious level of advertising.

\section{Government Regulation}

Governments have an opportunity and the responsibility to assume a leadership role in creating a more sustainable environment in which sustainable business can thrive, building conditions that promote sustainability (Bell, 2005). ${ }^{19}$ Aaronson \& Reeves (2002) compare Europe (mainly European Union) and the United States in terms of their approach and acceptance of the government's role in promoting CSR. According to the authors Aaronson \& Reeves, European companies have a greater possibility of accepting the governmental policies and collaborating with each other (Aaronson \& Reeves, 2002). ${ }^{20}$ European firms are more comfortable both working with government to

16 Porter, M. E., \& Kramer, M. R. (2011). Creating shared value.

17 Delios, A. (2010). How Can Organizations Be Competitive but Dare to Care?

18 Peikoff, L. (2010). Objectivism: the Philosophy of Ayn Rand.

19 Bell, D.V.J. (2005). The role of governance in advancing corporate sustainability.

20 Aaronson, S. \& Reeves, J. (2002). The European Response to Public Demands for Global Corporate 
improve social conditions and in a regulated environment. In other hand, North American organizations demonstrate more commitment, communication, and action (CBSR 2001). ${ }^{21}$ These facts state that governmental policies differ throughout the world in many ways. The value of governmental regulation for the consumers differs from one industry to another. So, it is in the insurance industry. Consumers in the end pay all costs of government involvement - as taxpayers, as buyers of services, as employees and as stakeholders in the companies involved. Evidence to date indicates that consumers are not being well served by a wide variety of insurance regulations. There are numerous beneficiaries of course, but they are not consumers. Developments in economic analysis and a host of empirical evidence accumulated in recent years leave no doubt that consumers' interest and the nation's overall economic welfare would be served by systematic and targeted reforms of out-of-date regulations. The rules of the marketplace sometimes fail and warrant government entry. Governmental regulations should encourage market efficiency, service innovation, lower industry costs, and lower prices for consumers.

Independent mediators, particularly the government, are causing a move to CSR policies in order to ensure that companies are prevented from harming people and the environment. Some argue for regulation that outlines how businesses should conduct themselves responsibly, but this presents problems as laws are unable to cover all details and issues of a corporation's operations. The road to universal CSR acceptance is rocky, but worth the effort. Betsy Atkins (2006) wrote an article for Forbes Magazine, “Is Corporate Social Responsibility Responsible?” She ends with a concise argument based on common sense that isn't so common any more:

"What the investing and consuming public really means by 'social responsibility' is:

- Be transparent in financial reporting

- Produce a quality product, and don't misrepresent it

- If you know something about the product that endangers the consumer, be forthright and let the public know (Tylenol)

- Do not use predatory practices in offshore manufacturing, such as child labor

- Do not pollute your environment or other environments, and adhere to laws and regulations

- Be respectful, fair and open in your employment practices

In other words, corporate social responsibility actually refers largely to what the company does not do. I think this is a clarification that should be understood by all constituencies" (Atkins, 2006).

\section{Summary and Future Recommendations}

During the preparation of this paper on CSR and related issues, this researcher realizes that a company's efforts in this area require a real partnership with their stakeholders and the society in which they function. It is very obvious to me, that firms that invest the time and resources to develop a comprehensive CSR policy are really investing in a social, economic, and environmental agenda. This will, in the long term impact the company, their stakeholders and society in a positive way. With this type of commitment from business it will also positively impact the perceived role of business in our society, and most important of all, the participants will have to communicate on a regular basis to allow for the ever-changing world that we all live in.

\section{CONCLUSION AND RECCOMENDATIONS}

We believe that CSR is going to be a part of our culture and our evolution as a society for a long time to come. Businesses have to recognize that they must be an active and willing partner in this process to survive. The increase of information and the globalization process creates a different business environment. In such an environment global politics, geo-politics, does tend to intrude as we make our arrangements to take our businesses to new national audiences, to work in different counties, to invest in different parts of the world, to dispatch our staff around the world, or care for overseas staff in our own domestic firmament.

Responsability.

21 CBSR. 2001. Government and Corporate Social Responsibility. An Overview of Selected Canadian, European and International Practices 
It is important to note that companies and shareholders relationship will evolve. All the parties in the CRS process need to continually educate themselves regarding societal concerns with environmental issues and other CSR concerns.

\section{References}

Aaronson, S. \& Reeves, J. (2002) The European Response to Public Demands for Global Corporate Responsibility. Washington, DC: National Policy Association.

Ahlstrom, D. (2010). Innovation and Growth: How Business Contributes to Society. Academy of Management Perspectives, 24(3), 11-24. Retrieved from EBSCO host Database.

Atkins, B. (2006, November 16). Forbes: "Is Corporate Social Responsibility Responsible?"

Bell, D.V.J. (2005). The role of governance in advancing corporate sustainability. Sustainable Enterprise Academy, York University, Toronto.

Bylo, A., \& Çankaya, S. (2019). Capital Structure Determinants in Transitional Economies. International Journal of Commerce and Finance, 5(1), 70-78.

CBSR. 2001. Government and Corporate Social Responsibility. An Overview of Selected Canadian, European and International Practices. Vancouver: Canadian Business for Social Responsibility.

Delios, A. (2010). How Can Organizations Be Competitive but Dare to Care? Academy of Management Perspectives, 24(3), 25-36. Retrieved from EBSCOhost Database

Hetzog, W. (2004, March 16). 3M. Retrieved online from Johnson, S. C. (2007, April 11). (IV). Retrieved online from http://www.scjohnson.com/community/default.asp

Kantor, R., \& Wells, R. (2004). Book: "Innovation: Breakthrough thinking at 3M (etc.)." Retrieved online from Strategizing for the Future. Retrieved online from http://www.tbl.com.pk/csr-strategy-in-developingcountries/

Maden, J. (2008). Wikipedia definition of CSR. Retrieved online from http://en.wikipedia.org/wiki/Corporate_social_responsibility

Mcgreson, P. (2006, June 6). Costco story. Retrieved online from Http://www.fool.com/ahead-of-thecurve/2006/ahead-of-the-curve-06112201.htm date-2006 June 6 http://www.fool.com/ahead-of-thecurve/2006/ahead-of-the-curve-06112201.htm\%20Date-2006\%20June\%206

Michels, D. (2008). From genetic engineering \& biotechnology news (a shot at the idea), Retrieved online from http://www.genengnews.com/blog/item.aspx?id=347

News about csr (2010). Retrieved online from <http://www.csrwire.com/about>.

Peikoff, L. (2010). Objectivism: The Philosophy of Ayn Rand, (New York, Meridian 1991)

Porter, M. E., \& Kramer, M. R. (2011). Creating shared value. Harvard Business Review, 89(1/2), 62-77. Retrieved from EBSCOhost Database.

Truetv (1982). Tylenol Case. Retrieved online from http://www.trutv.com/library/crime/terrorists_spies/terrorists/tylenol_murders/2.html

Sarbanes-Oxley Act of 2002, Public Law 107-204. Retrieved online from: http://fl1.findlaw.com/news.findlaw.com/hdocs/docs/gwbush/sarbanesoxley072302.pdf

Wetzler, P. (1994). History of Post-It notes - please read this, he's not only an inventor, he's http://www.rakemag.com/reporting/features/twenty-five-years-post-it-notes-0

Younkins, E. (2000). The Free Radical. Individual Rights, Social Responsibilities, and Corporations. 